\title{
CONHECIMENTO DO TEMA OFIDISMO ENTRE FUTUROS PROFESSORES DE CIÊNCIAS BIOLÓGICAS DO ESTADO DO CEARÁ
}

\author{
Knowledge of the snakes theme in future \\ Biological Sciences teachers from the State of Ceará
}

\author{
Déborah Praciano Castro ${ }^{1}$. Daniel Cassiano Lima²
}

\begin{abstract}
Resumo: Os temas ligados ao ofidismo são bastante enfatizados entre os assuntos da saúde pública. Partindo da premissa de que biólogos devem possuir conhecimento básico sobre identificação de serpentes, e noções sobre sintomatologia e tratamento de acidentes com estes animais, verificamos os conhecimentos teóricos e práticos sobre ofidismo entre alunos dos cursos de Ciências Biológicas do Estado do Ceará. Foi aplicado um questionário com questões teóricas e práticas, abordando a temática do ofidismo, a 67 alunos de três Instituições de Ensino Superior, que haviam cursado as disciplinas curriculares que abordavam serpentes. Os dados obtidos demonstraram pouco conhecimento do tema pela maioria dos entrevistados, que apresentaram conceitos obsoletos e incorretos, desconhecendo conceitos básicos sobre a biologia destes animais, e dificuldades para diferenciá-los de outros animais serpentiformes. Sugere-se inclusão mais efetiva do tema no Ensino Superior, uma vez que o ofidismo é um problema presente em todas as regiões do Brasil.
\end{abstract}

Palavras-chave: Serpente. Ofidismo. Formação de professores. Ensino Superior. Ensino de Biologia.

\begin{abstract}
The ophidism and all relative themes are subjects discussed among the Public Health problems. On the premise that biologists have basic knowledge about identifying snakes, as well as notions about symptoms and treatment of accident with snakebites, we sought to know how this content is covered in Biological Sciences courses in the state of Ceará. We applied one questionnaire with theoretical and practical questions to 67 graduate students, all of them approved in the disciplines of their curriculum that involved the topic of snakes. The data analysis that the theme is little known by most of the respondents, who had outdated and incorrect concepts. Most of them don't know the basics about the biology of these animals and had difficulties to distinguish them from other snakelike animals. We suggest an effective inclusion of the subject in higher education, since the snakebite is a problem present in all regions of Brazil.
\end{abstract}

Keywords: Snake. Ophiology. Teacher training. Higher education. Biology education.

\footnotetext{
${ }^{1}$ Centro de Ciências, Universidade Federal do Ceará, Programa de Pós-Graduação em Ecologia e Recursos Naturais, Núcleo Regional de Ofiologia. Avenida Humberto Monte, s/n, campus do Pici. CEP 60455-760, Fortaleza, CE, Brasil. <deborahpraciano@yahoo.com.br>

${ }^{2}$ Centro de Ciências Naturais e Exatas, Universidade Federal de Santa Maria, Programa de Pós-graduação em Biodiversidade Animal, Santa Maria, RS. Brasil. Faculdade de Educação de Itapipoca (Facedi), Itapipoca, CE, Brasil.
} 


\section{A formação de professores nos cursos de licenciatura}

Uma das preocupações da educação é a melhoria da formação de seus profissionais. Para isso, desde a década de 1960, houve a publicação de documentos que tinham o intuito de reger os processos educacionais existentes no país, como a Lei 4.024/1961 (BRASIL, 1961), Lei 5.692/1971 (BRASIL, 1971) e a atual Lei de Diretrizes e Bases da Educação Nacional (LDB, Lei 9.394/1996) (BRASIL, 1996).

Briscoe (1991) já alertava para o fato de que o modo de transmissão do conhecimento, da forma por ele considerada tradicional, apenas demonstrava que os profissionais formados não teriam o preparo necessário em seus cursos de formação, e nem conseguiriam capacitar, de maneira eficaz, os seus futuros alunos. O problema da formação parecia estar relacionado ao fato de que a compreensão da disciplina lecionada deveria implicar a capacidade profissional de sintetizar conteúdos de origens muitas vezes diversas, incluindo abordagens que, normalmente, não são mencionadas nos cursos universitários (COLL, 1987; BROOME, 1988). Na maioria dos casos, a amplitude dos currículos e a pouca disponibilidade de tempo para a dedicação aos diferentes temas impediram uma melhor apropriação de determinados conceitos de maneira satisfatória, não havendo uma maior discussão sobre qual profissional se pretendia formar (GATTI, 2000).

Estas deficiências já haviam sido detectadas por Carvalho e Gil-Pérez (2003), que afimam que os profissionais, quando confrontados com assuntos básicos, apresentavam respostas evasivas e pouco fundamentadas, levantando a possibilidade de que o seu processo formador tenha apresentado uma série de transtornos. Gatti (2000) informou que, historicamente, o processo de formação de licenciados tem evidenciado diversas lacunas, quanto ao conhecimento pedagógico e aspectos específicos de cada área. Para Zanotto (2000), a detecção deste viés do conhecimento seria fundamental para que o professor seja bem-sucedido em seu trabalho de ensinar.

A formação acadêmica deve ser suficiente para capacitá-los a responder e superar as perspectivas do mundo atual diante dos novos avanços do conhecimento cientifico e tecnológico (VASCONCELOS; LIMA, 2010). Diante deste fato, é necessário repensar, de forma significativa, o processo de formação de professores, de modo a contemplar as relações necessárias entre os diferentes saberes e entre a teoria e a prática, em perspectivas inter e multidisciplinar, visando à totalidade (ZAKREVSKI; BIELUCZYK; CICLO, 2006).

Segundo Gil-Pérez (1983), esse processo de formação interdisciplinar precisa atuar de forma efetiva no currículo, de modo a transformar um currículo básico voltado para o tradicionalismo em algo de maior aplicabilidade. Vasconcelos e Lima (2010) compartilham desse mesmo pensamento, afirmando que:

Professores de ciências são elementos-chave nas mudanças dos indicadores negativos do nosso ensino: além de trabalharem o conteúdo, atuam ativamente como mediadores no processo de inclusão científica e tecnológica dos cidadãos, contribuindo para aproximar as ciências do cotidiano do estudante. (VASCONCELOS; LIMA, 2010, p. 324) 


\section{O caso do ofidismo no ensino formal}

Levando em conta que o processo de aprendizagem em Ciências inclui a necessidade de formação de bons professores, que possam ter a capacidade de perceber que somente o 'dom' de ensinar não é suficiente, mas, sim, uma boa formação inicial e continuada ligada ao cotidiano (GEBARA, 2001), é preciso utilizar as noções básicas sobre assuntos relevantes.

Melgarejo (2003) cita, como exemplo de um destes assuntos, os acidentes ofídicos, por constituírem estes uma problemática que pode ser vivenciada pelos estudantes em qualquer nível educacional. Acidentes ofídicos são considerados problemas de saúde pública (BOCHNER; STRUCHINER, 2003; PARDAL et al., 2007), e podem estar relacionados tanto a área rural quanto com grandes centros urbanos, que enfrentam a problemática da falta de estrutura adequada de saneamento básico, associada a maus hábitos sociais (WEN et al., 2002; MELGAREJO, 2003).

Embora encontros com serpentes e casos de acidentes ofídicos sejam frequentes (LIMA-VERDE, 1994), o desconhecimento sobre estes animais é grande. Real, Gianine e Fischer (2000) relataram que, em palestras ministradas a alunos de Biologia e professores na cidade de Sorocaba, SP, encontraram profissionais que mantinham total desconhecimento de temas ligados ao ofidismo. Lima, Castro e Lima (2010) realizaram pesquisa semelhante entre estudantes de uma instituição de Ensino Superior no Ceará, e perceberam vários equívocos entre as suas respostas, levando os autores a sugerirem que estudos semelhantes também fossem aplicados em outras unidades de Ensino Superior.

Couto (2008), em estudo de caso realizado no município de Itapipoca, CE, citou as dificuldades dos alunos de Ensino Médio ao associarem corretamente conteúdos referentes a serpentes peçonhentas. $\mathrm{O}$ estudo demonstrou que certos alunos identificavam os animais a partir de conteúdos obsoletos, e sugeriu que este fato pode estar ligado à ocorrência de os professores de ciências repassarem informações incorretas, provenientes dos próprios livros didáticos, da mesma forma como foi registrado anteriormente por Sandrin, Puorto e Nardi (2005).

Ao que parece, o problema da falta de informação quanto a serpentes e acidentes ofídicos não é recente, e nem restrito aos cursos de formação de professores. Real, Gianine e Fischer (2000) concluíram que os cursos de graduação na área da saúde não têm fornecido conhecimentos básicos para o manejo de pacientes vítimas de ofidismo, e, embora algumas ações tenham sido tomadas para reverter tal realidade, Mise, Silva e Carvalho (2007) informaram que $44 \%$ das escolas médicas ainda não preparam seus profissionais para o tratamento de acidentes ofídicos.

Partindo da premissa de que alunos do curso de licenciatura em Ciências Biológicas devem possuir o conhecimento básico para a identificação superficial de animais, devido ao contato com as disciplinas de zoologia e sistemática animal, nas quais trabalham temas que abordam classificação, diferenciação e uso de chaves dicotômicas, este trabalho analisa o conhecimento sobre os temas ligados ao ofidismo entre alunos dos cursos de Ciências Biológicas do estado do Ceará, além de verificar seus conhecimentos sobre a diferenciação de serpentes e outros animais serpentiformes, bem como a sintomatologia dos acidentes ofídicos. 


\section{Materiais e métodos}

Para esta pesquisa, foram considerados apenas estudantes dos cursos de licenciatura em Ciências Biológicas do estado do Ceará, devidamente reconhecidos pelo Conselho de Educação. Além desta condição, os participantes da pesquisa deveriam ter cursado disciplinas que abordassem o conteúdo referente ao grupo dos cordados, onde supostamente obtiveram os conhecimentos relativos às serpentes.

As atividades foram realizadas nas seguintes instituições (Figura 1): Universidade Estadual do Ceará (UECE), nos campi dos municípios de Itapipoca (Faculdade de Educação de Itapipoca - FACEDI), Iguatu (Faculdade de Ciências e Letras de Iguatu - FECLI), e Fortaleza (Centro de Ciências da Saúde - CCS); Universidade Estadual Vale do Acaraú (UEVA) do município de Sobral, CE; e Universidade Federal do Ceará (UFC) em Fortaleza, CE. As escolhas dos locais de realização da atividade foram realizadas previamente por meio de autorização dos coordenadores de cada curso, e os alunos podiam optar participar ou não da pesquisa.

Embora, a pesquisa tenha sido aplicada em três diferentes campi da Universidade Estadual do Ceará, para efeito das análises dos resultados, foram agrupados em uma única categoria, o que é justificável pelo fato de a Universidade adotar um currículo comum para todos os campi.

Foi aplicado um questionário (documento suplementar) - composto por cinco questões teóricas e quatro práticas, cujos assuntos variavam desde a identificação de animais serpentiformes até a sintomatologia e tratamento de acidentes - a ser respondido individualmente. O questionário foi estruturado de modo semelhante ao aplicado por Vasconcelos e Lima (2010), que trata do perfil de licenciados em universidades públicas. Antes do início da ativida-

Figura 1. Localização das cidades onde foi realizada a pesquisa.

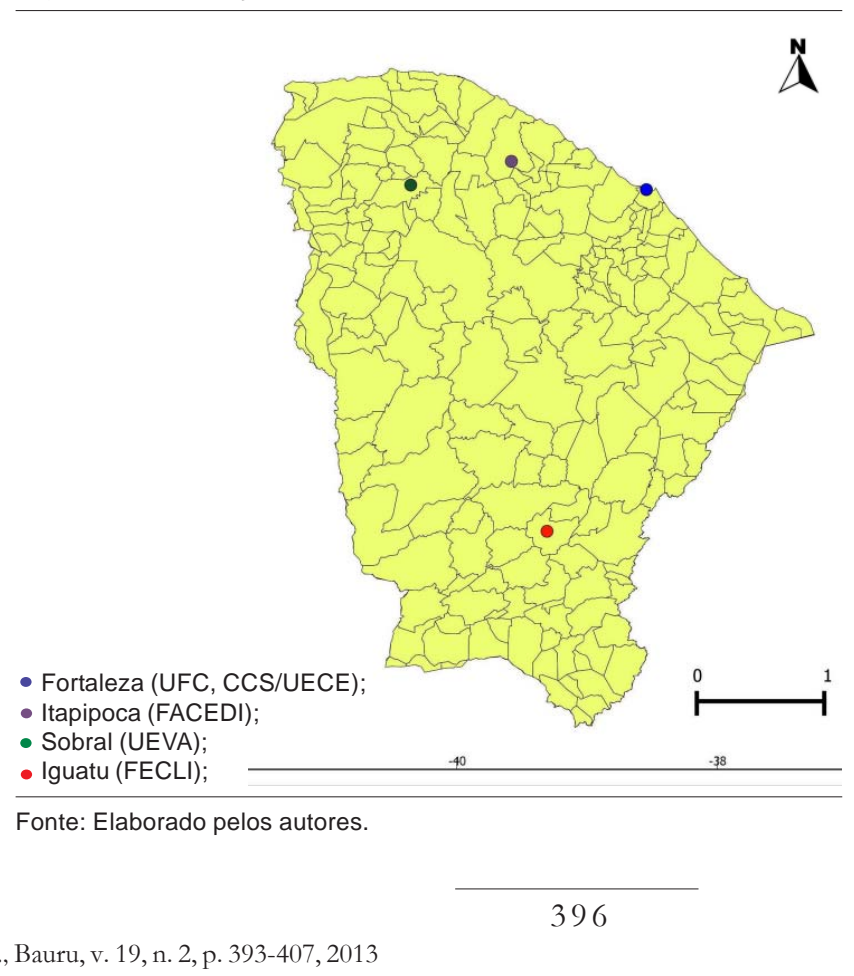

Ciênc. Educ., Bauru, v. 19, n. 2, p. 393-407, 2013 
de, cada estudante foi orientado individualmente sobre as instruções de preenchimento, e dúvidas eventuais foram tiradas. Comentários expressos nas formas verbal ou escrita foram registrados.

As questões de cunho prático foram realizadas nos laboratórios das instituições de ensino, onde foram montadas bancadas contendo os materiais relativos a cada questão. $\mathrm{O}$ material era composto de exemplares de serpentes das seguintes famílias: Boidae, Colubridae, Dipsadidae, Elapidae, Leptotiphlopydae e Viperidae, todas ocorrentes na região Nordeste do Brasil. Também foram utilizados outros animais serpentiformes, como peixes (Ordem Dipnoi), anfíbios (Ordem Gymnophiona) e répteis (Ordem Squamata), todos fixados em formol 10\% e obtidos a partir das coleções didáticas da FACEDI e do Núcleo Regional de Ofiologia (NUROF) da Universidade Federal do Ceará (UFC). Apenas para uma questão relativa à dentição das serpentes não foi utilizado material biológico. Neste caso, foram utilizadas as ilustrações (Figura 2) ampliadas disponibilizadas por Franco (2003).

\section{Resultados e discussão}

A amostra total de participantes da pesquisa contou com 67 alunos, divididos da seguinte forma: FACEDI/UECE ( $\mathrm{n}=12)$, FECLI/UECE ( $\mathrm{n}=3)$, CCS/UECE ( $\mathrm{n}=28), \mathrm{UFC}(\mathrm{n}=11)$ e UEVA ( $n=13)$. Para efeito de análise dos questionários, os alunos dos três primeiros cursos citados foram reunidos em uma amostra única, por apresentarem currículo comum, o que torna a UECE a instituição com maior número de estudantes da pesquisa, com 43 participantes.

Figura 2. Ilustração mostrando os quatro tipos básicos de dentição das serpentes.

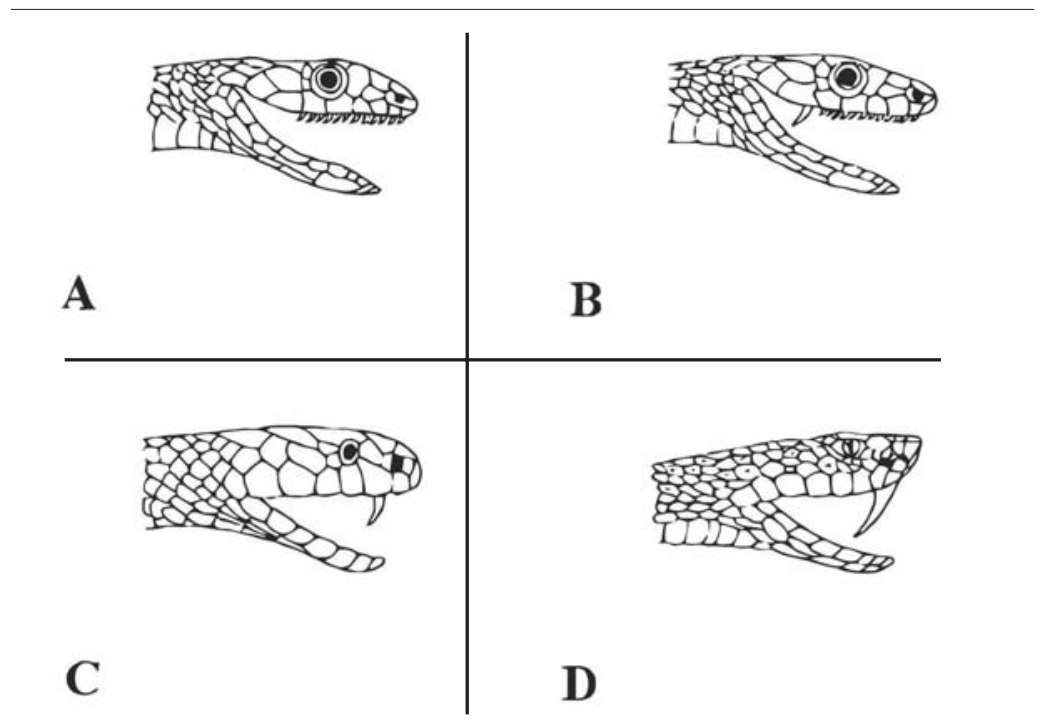

A. áglifa; B. opistóglifa; C. proteróglifa; D. solenóglifa.

Fonte: Adaptado de Franco (2003). 
A princípio foi perceptível que alguns alunos tinham dificuldade até mesmo para entenderem os conceitos apresentados nas questões, sendo comuns perguntas do tipo "O que é constrição?" durante a atividade. A maior parte $(56,71 \%)$ do total de participantes associou os hábitos de obtenção de alimento das serpentes de forma equivocada, e 43,28\% consideraram a jararaca Bothrops erythromelas (Amaral, 1923), e a cascavel Crotalus durissus (Linnaeus, 1758) como constritoras. Enquanto isso, 13,43\% apontaram a sucuri Eunectes murinus (Linnaeus, 1758) como envenenadora (Gráfico 1). Este resultado evidenciou parte do desconhecimento de conceitos básicos ou mesmo populares, pois, culturalmente, as cascavéis e jararacas são reconhecidas como potencialmente perigosas, sobretudo por sua picada; ao mesmo tempo em que os mitos das "sucuris engolidoras de homens", que "abraçam" e "apertam" suas presas para, posteriormente, engolirem, são também amplamente divulgados. Embora serpentes também possam utilizar uma outra estratégia alimentar conhecida como deglutição, onde as presas podem ser engolidas vivas (POUGH; JANIS; HEISER, 2008), para esta pesquisa, apenas utilizamos espécies constritoras e peçonhentas.

Gráfico 1. Verificação do conhecimento dos estudantes quanto à associação de serpentes ao modo de captura dos alimentos.

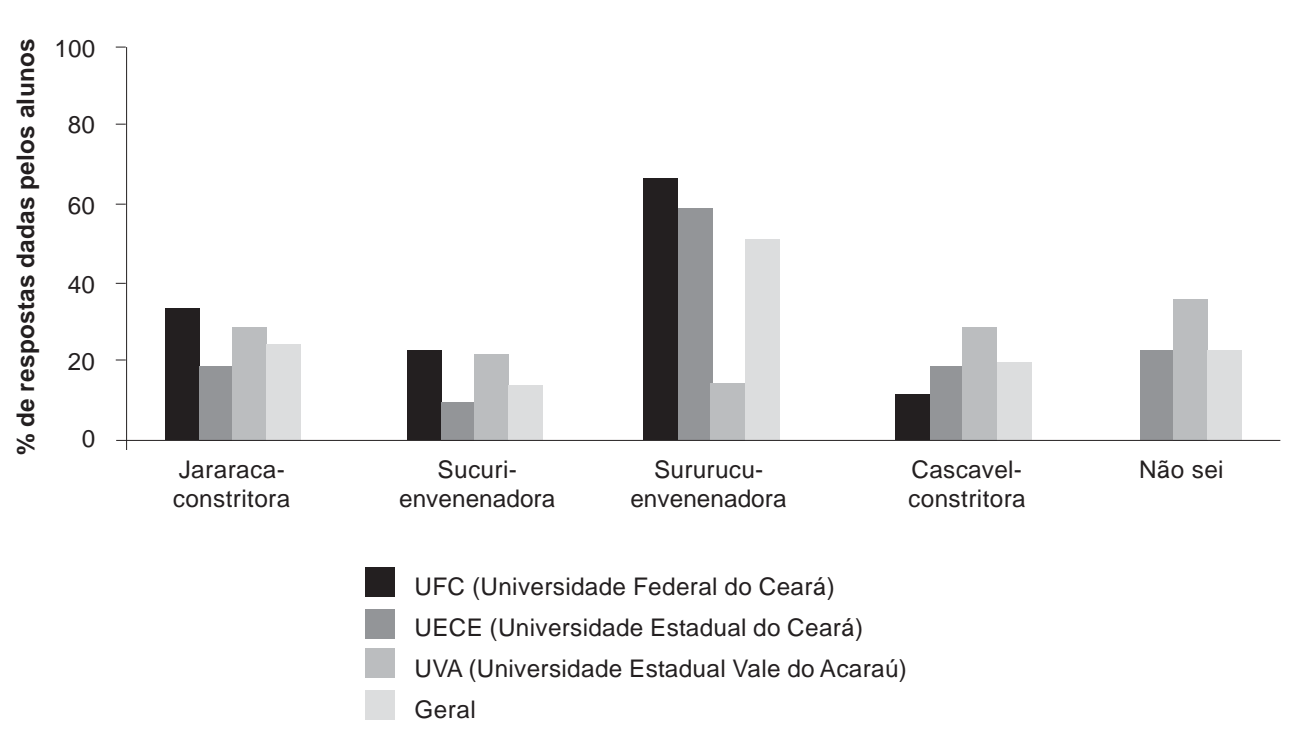

Fonte: Elaborado pelos autores.

Equívocos semelhantes foram verificados quando os alunos deveriam apontar características seguras que permitissem diferenciar serpentes de interesse médico daquelas que não são. A maioria dos participantes apontaram características difundidas popularmente como meio de distinção (Gráfico 2), tais como: olhos pequenos (13,43\%), pupila vertical (23,88\%), cabeça triangular $(44,77 \%)$ e padrão de anéis completos $(23,88 \%)$. Estas afirmações corrobo- 
ram as constatações de Sandrin, Puorto e Nardi (2005), e parecem refletir o conhecimento obtido em séries anteriores à universidade, onde a maioria dos livros apresenta conceitos equivocados, a exemplo dos assinalados na pesquisa. O fato também aponta para o processo de formação de professores, que utilizarão estes livros didáticos, que oscila entre a especificidade disciplinar e a generalidade, cabendo a reflexão sobre que tipo de profissionais estão sendo formados (CARVALHO; GIL-PÉREZ, 2003).

Gráfico 2. Conhecimento dos estudantes quanto às características que distinguem com segurança serpentes peçonhentas de não peçonhentas.

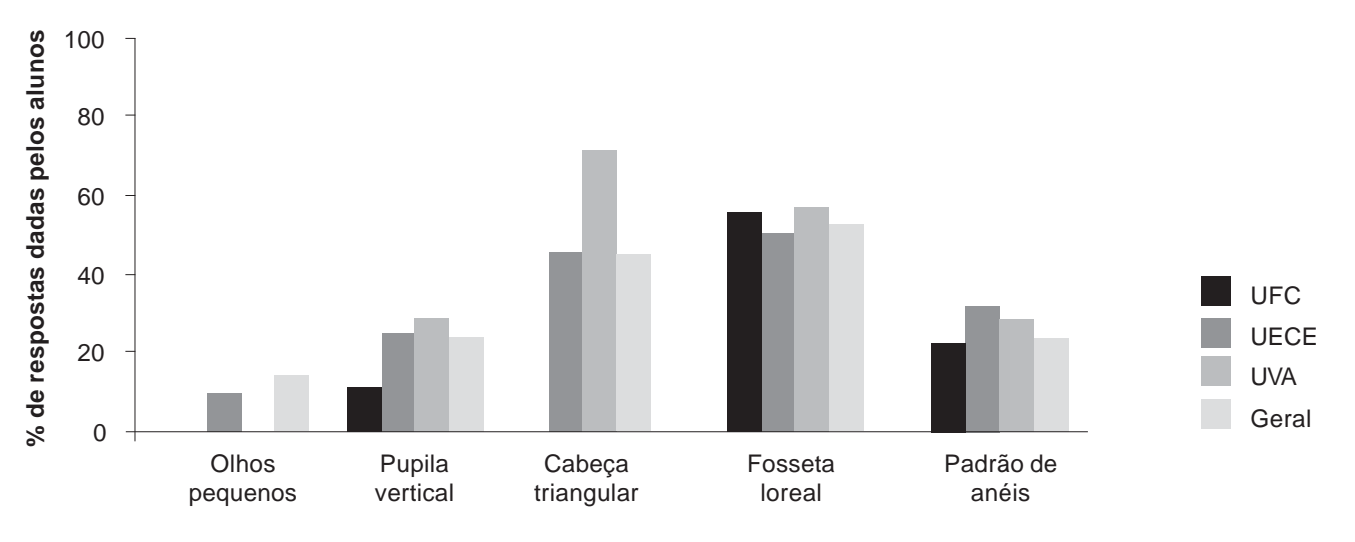

Fonte: Elaborado pelos autores.

Algumas características tradicionalmente utilizadas para distinguir serpentes peçonhentas e não peçonhentas podem tornar mais confusa a identificação, como citam Sandrin, Puorto e Nardi (2005), ao mencionarem que, no Brasil, existem serpentes peçonhentas com cabeças que se destacam do corpo, assim como serpentes não peçonhentas como os Boídeos, representados por jiboias, Boa constrictor (Linnaeus, 1758); salamantas, Epicrates cenchria (Linnaeus, 1758), e sucuris, Eunectes murinus (Linnaeus, 1758). O mesmo pode ser dito com relação a características como pupilas verticais ou tamanho dos olhos. De forma diversa, corais verdadeiras apresentam cabeças arredondadas, não sendo este critério válido para sua identificação. O padrão de anéis também é um caráter impreciso, já que este pode variar bastante, dependendo da espécie ou distribuição geográfica (MELGAREJO, 2003).

A identificação errônea de exemplares peçonhentos pode ocasionar reações desnecessárias contra serpentes inofensivas. Nascimento (2000), e Lima, Castro e Lima (2010) citam o caso de Leptodeira annulata (Linnaeus, 1758), uma espécie não peçonhenta, mas que, por ter coloração similar à das jararacas, é reconhecida como tal pela população, e acaba sendo morta desnecessariamente.

A fosseta loreal citada em 52,23\% das respostas aos questionários é um órgão situado abaixo da linha que separa o olho da narina, e que está presente nos viperídeos da subfamília Crotalinae. Segundo Melgarejo (2003), a presença da fosseta loreal é seguramente um fator de 
identificação de serpentes peçonhentas, já que 99\% dos acidentes ofídicos no Brasil são causados por animais que as possuem.

Com relação à diferenciação entre corais verdadeiras (família Elapidae) e falsas (Famílias Colubridae e Dipsadidae), os estudantes também apresentaram conhecimentos errôneos. Eles apontaram pupila vertical $(10,44 \%)$, cabeça triangular $(19,40 \%)$ e fosseta loreal $(25,37 \%)$ como formas de distinção entre os dois grupos (Gráfico 3). Nenhuma das características pode ser usada para esta diferenciação, uma vez que várias espécies de corais verdadeiras e falsas podem apresentar pupila vertical, e nenhuma delas tem cabeça em formato triangular ou fosseta loreal (VANZOLINI; RAMOS-COSTA; VIT'T, 1980). O padrão de anéis completos presente em corais verdadeiras (Família Elapidae), apontado por 61,19\% dos avaliados, também não é uma característica segura, uma vez que falsas corais como as do gênero Erythrolamprus Boie, 1826, podem apresentar padrão similar ao das corais verdadeiras.

Gráfico 3. Respostas dos estudantes sobre as características que diferenciam corais verdadeiras e falsas.

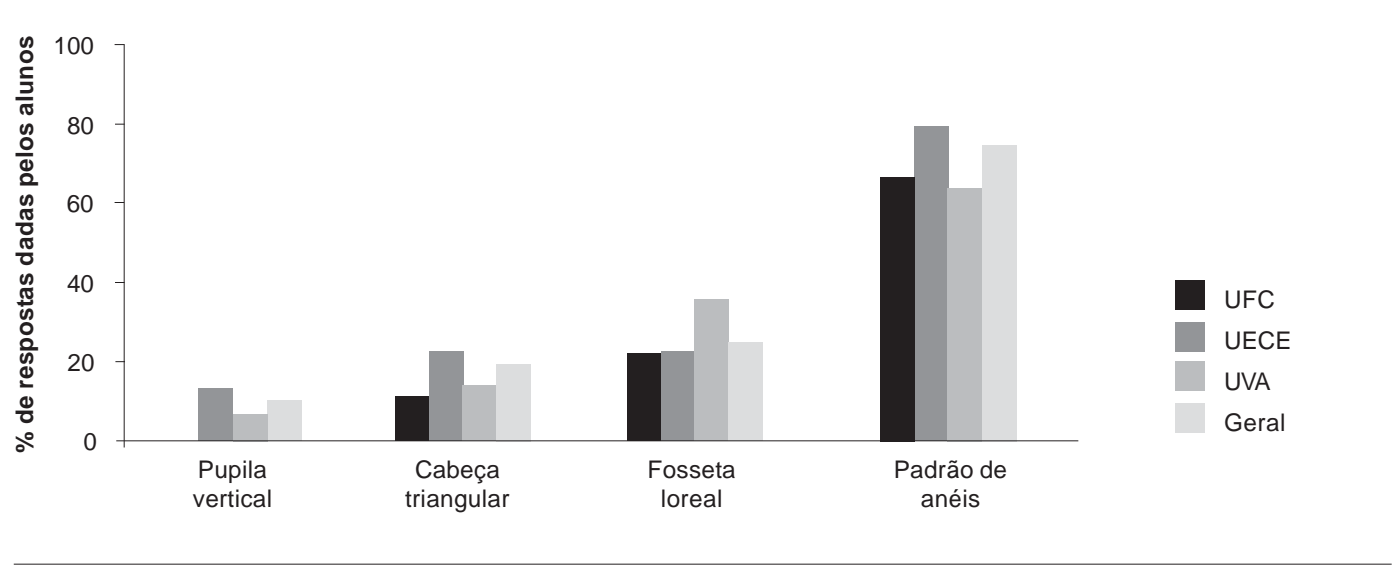

Fonte: Elaborado pelos autores.

A situação também se mostrou preocupante quando os graduandos tiveram dificuldade de diferenciar serpentes de outros vertebrados ápodos. Embora 83,58\% deles tenham reconhecido serpentes das famílias Colubridae ou Dipsadidae como serpente, e 31,34\% um exemplar de Leptotyphlopidae, grande número ainda considera outros animais serpentiformes - tipo: anfisbenas, Amphisbaena alba (Linnaeus, 1758) (14,92\%); anfíbios ápodos, Chthonerpeton arii Cascon \& Lima-Verde, 1994 (2,98\%); lagartos ápodes, Ophiodes striatus (Spix, 1825) (16,41\%); e mussuns (peixes, Dipnoi) (7,46\%) - exemplares de serpentes (Gráfico 4).

Este estudo evidencia a necessidade de uma reflexão profunda sobre que aspectos do conhecimento os graduandos estão construindo dentro da universidade, visto apresentarem dificuldades na distinção de animais estudados separada e detalhadamente em disciplinas de Zoologia do currículo básico de cursos de Ciências Biológicas. Durante a resolução desta 
questão, uma das estudantes escreveu um comentário que pode ser o ponto inicial ou conclusivo desta reflexão: "[...] é nessa hora que eu fico pensando onde ficaram as milhões de zoologias que a gente fez”" (sic). A situação pode passar a falsa impressão de que muitos dos aspectos conceituais dentro da biologia não são ministrados nos cursos de graduação. É provável, no entanto, que a realidade reflita a dicotomia amplitude do currículo versus o pouco tempo dedicado às disciplinas, conforme exposto por Gatti (2000).

Gráfico 4. Animais identificados como serpentes pelos participantes.

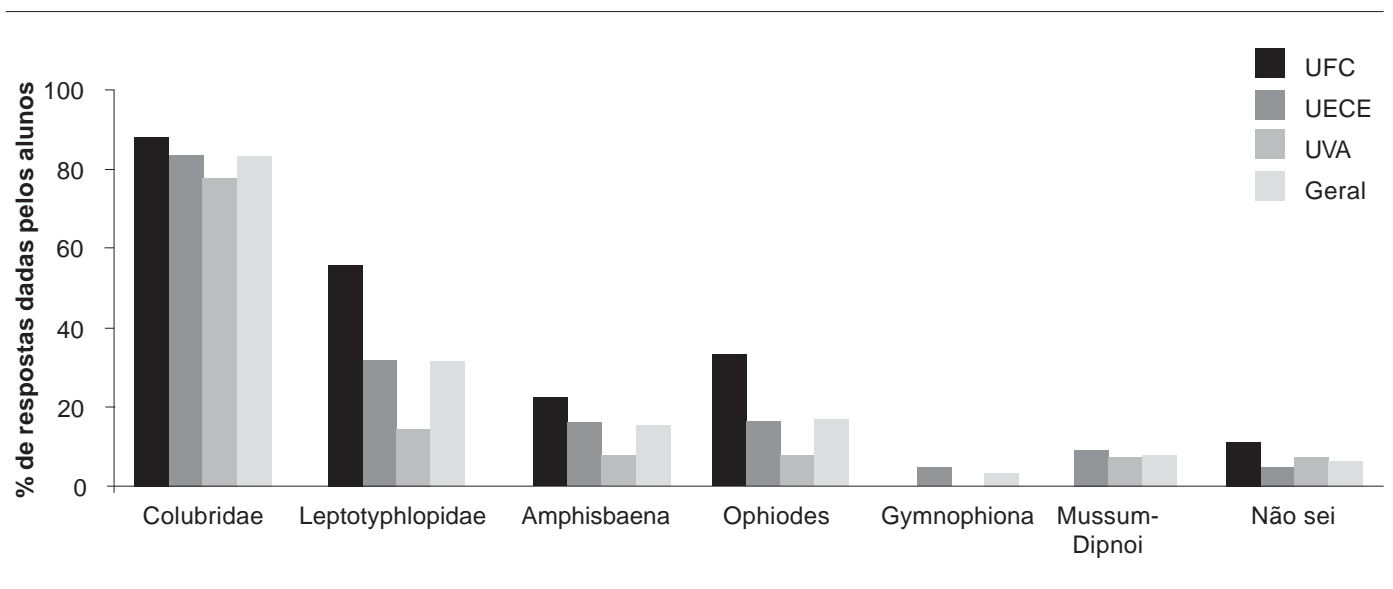

Fonte: Elaborado pelos autores.

Foram apresentadas, aos estudantes, ilustrações contendo os quatro tipos de dentições presentes nas serpentes, para que fossem feitas as devidas associações. Um número considerável $(64,17 \%)$ não conseguiu diferenciar as dentições apresentadas, outros 19,4\% afirmaram "não sei" ao questionamento (Gráfico 5). Os padrões de dentição das serpentes apresentam especializações de acordo com o seu hábito alimentar (FRANCO, 2003; MELGAREJO, 2003), podendo as marcas das presas ser utilizadas no diagnóstico diferencial em alguns casos de acidentes ofídicos, pois, nem sempre, as marcas das presas podem ser visualizadas (FRANÇA; MALAQUE, 2003).

Quando indagados sobre as medidas que devem ser utilizadas em casos de acidentes ofídicos com serpentes peçonhentas, a maioria apontou medidas aceitas pela Organização Mundial de Saúde, tais como: aplicação de soro específico, evitar movimentos e procurar ajuda médica (88,05\% e 85,07\%) (Gráfico 6) (MISE; SILVA; CARVALHO, 2007). No entanto, é necessário ressaltar que procedimentos errôneos e até agravantes, tais como o uso de torniquetes e ingestão de bebidas alcoólicas e querosene, foram citados por 1,49 \% dos participantes. Embora essa porcentagem seja um número bem pequeno da amostra, o fato de ela ser citada ressalta a crença em métodos obsoletos de cuidados emergenciais frente a acidentes ofídicos (PINHO; PEREIRA, 2001). 


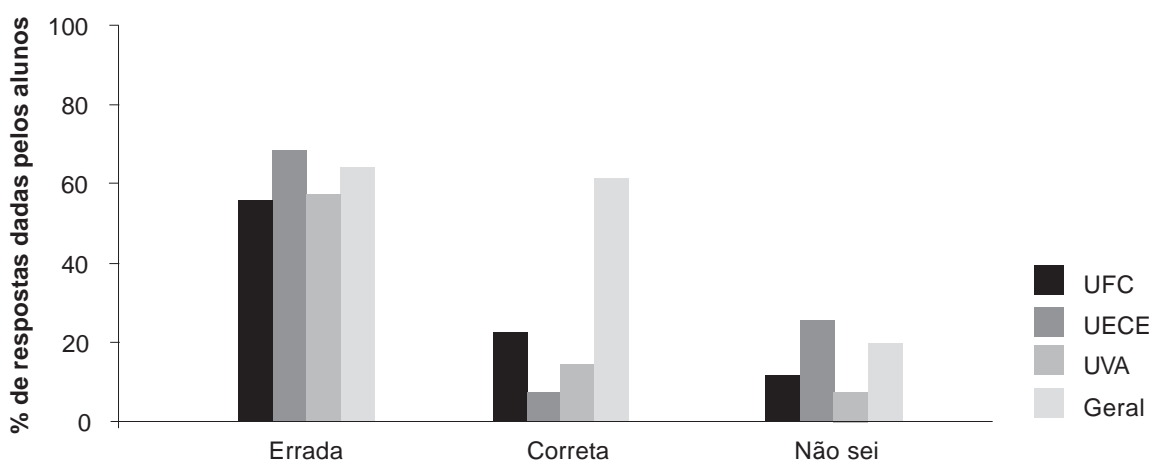

Fonte: Elaborado pelos autores.

Gráfico 6. Indicações dos tratamentos em caso de acidentes ofídicos por parte dos estudantes.

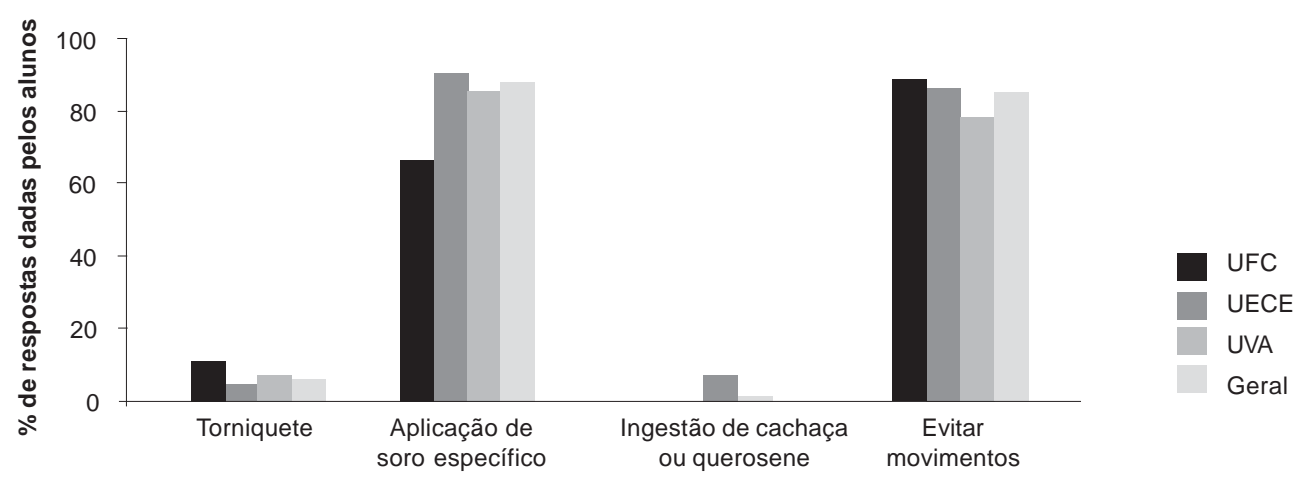

Fonte: Elaborado pelos autores.

O uso de torniquetes é bastante popularizado e, dependendo do caso, pode agravar o quadro clínico dos acidentados com serpentes (PINHO; PEREIRA, 2001). Sandrin, Puorto e Nardi (2005) citam que muitos livros didáticos ainda recomendavam o uso de torniquetes, bem como que o local da picada seja sugado. A questão da ingestão de determinadas substân-

\footnotetext{
${ }^{3}$ As respostas foram consideradas corretas quando os estudantes conseguiam associar os quatro tipos de dentições às espécies que os possuíam. 
cias também está ligada ao conhecimento popular. Ribeiro, Jorge e Iversson (1995), assim como Pinho, Oliveira e Faleiros (2004), relataram casos de populares que recomendavam a utilização de cachaça ou querosene, e, ainda, o uso tópico de fumo, esterco e outros remédios caseiros, todos com ineficácia comprovada (PEREIRA-NETO, 2000).

$\mathrm{Na}$ maioria das vezes, quando a identificação do ofídio causador do acidente não é possível, o quadro sintomático do paciente pode levar ao reconhecimento da espécie, tornando o tratamento sorológico mais objetivo (BOFF, 2005). Nenhum dos participantes associou corretamente os sintomas dos acidentes às serpentes que os ocasionaram (Gráfico 7). Um dos participantes enfatizou que não tinha como responder a este tipo de questionamento porque, durante a graduação, jamais se deparou com o assunto.

Gráfico 7. Conhecimento dos estudantes sobre a sintomatologia dos acidentes ofídicos4

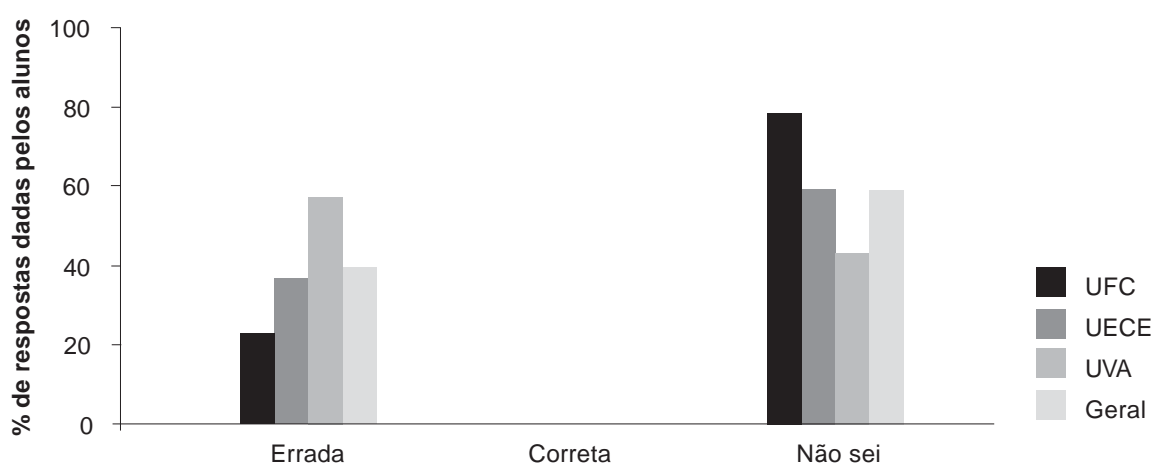

Fonte: Elaborado pelos autores.

De forma geral, as serpentes não constituem um grupo de animais carismáticos, despertando aversão até mesmo entre profissionais das ciências biológicas, o que pôde ser verificado nas falas de alguns dos participantes da pesquisa. Foram comuns algumas expressões e palavras enquanto o material era manuseado ou, mesmo, receio de tocar no material, mesmo com pinças à disposição. Expressões como: "Ai que nojo"; "Não quero tocar nesse bicho, ele é muito feio", foram utilizadas constantemente.

A UFC foi o centro universitário que apresentou uma maior quantidade de pessoas que já trabalharam com serpentes (Gráfico 8), provavelmente devido à existência de um centro de referência regional, o Núcleo Regional de Ofiologia (NUROF), que também desenvolve pesquisas não apenas com serpentes, mas, também, com outros répteis e anfíbios.

\footnotetext{
${ }^{4}$ As respostas foram consideradas corretas quando os estudantes conseguiram associar os sintomas clínicos presentes nos acidentados à serpente que ocasionou o acidente.
} 
Gráfico 8. Percentual dos estudantes que haviam trabalhado com serpentes durante a graduação.

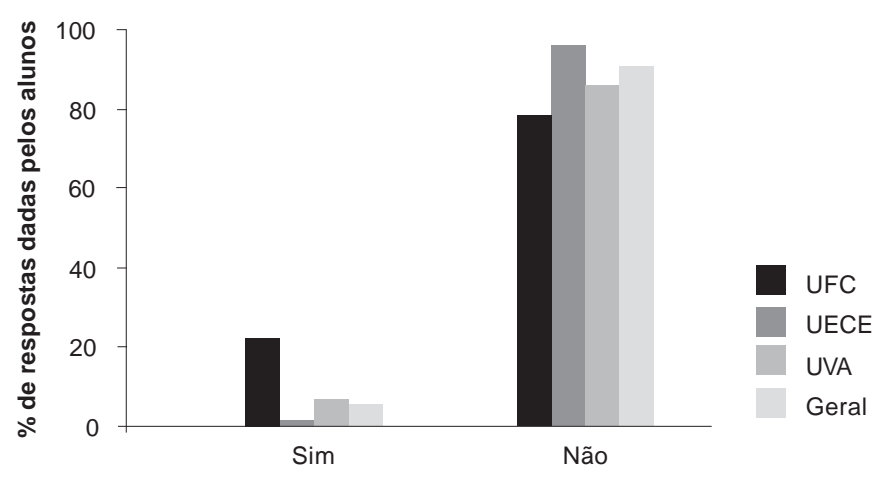

Fonte: Elaborado pelos autores.

\section{Considerações finais}

O ofidismo é considerado um problema de saúde pública. Conhecimentos a respeito da identificação correta dos animais, seus hábitos, ou a sintomatologia desenvolvida após os acidentes, podem auxiliar no correto diagnóstico, tratamento dos acidentados, e, até mesmo, na desmistificação destes animais. Apesar de terem contato com ofídios durante a graduação, os alunos dos cursos de Ciências Biológicas do Ceará apresentaram equívocos e conceitos obsoletos relativos à biologia dos animais, algo comparável ao conhecimento leigo sobre o assunto.

Provavelmente, a inserção do tema de forma mais direta e enfática permita um maior contato dos estudantes com o universo das serpentes, atenuando mitos, crendices, ou, mesmo, o medo irracional que, muitas vezes, mistifica os animais e seu comportamento. Apesar de o problema do ofidismo não ser abordado de forma direta nas disciplinas em que se estudam as serpentes, sua abordagem poderia ser trabalhada, inclusive, de forma interdisciplinar, de modo que as diferentes vertentes do problema pudessem ser satisfatoriamente trabalhadas.

Este trabalho pode ser o indicativo de que outros temas, inclusive, podem estar sendo trabalhados com menor importância, mas que provavelmente sejam tão importantes na prática, e de aplicação cotidiana imediata. Sobretudo os futuros professores deveriam estar mais preparados para lidar com tais assuntos em sala de aula, rompendo ciclos de aprendizado vicioso. 
Conhecimento do tema ofidismo ...

\section{Referências}

BOCHNER, R.; STRUCHINER, C. J. Epidemiologia dos acidentes ofídicos nos últimos 100 anos no Brasil: uma revisão. Cadernos de Saúde Pública, Rio de Janeiro, v. 19, n. 1, p. 7-16, 2003.

BOFF, G. J. Envenenamento por picada de serpente - gênero Crotalus: revisão. Veterinária em Foco, Canoas, v. 3, n. 1, p. 79- 92, 2005.

BRASIL. Lei 4.024 de 20 de dezembro de 1961. Fixa as diretrizes e bases da educação nacional. Disponível em: <http://www.planalto.gov.br/ccivil_03/leis/14024.htm>. Diário Oficial da União, Brasília, 27 dez. 1961. Acesso em: 08 abr. 2013.

Lei 5.692 de 11 de agosto de 1971 . Fixa diretrizes e bases para o ensino de $1^{\circ}$ e $2^{\circ}$ graus, e dá outras providências. Diário Oficial da União, Brasília, 12 ago. 1971. Disponível em: < http://www.planalto.gov.br/ccivil_03/leis/15692.htm>. Acesso em: 08 abr. 2013.

Lei 9.394 de 20 de dezembro de 1996. Estabelece as diretrizes e bases da educação nacional. Diário Oficial da União, Brasília, 23 dez. 1996. Disponível em: <http:/ / www.planalto.gov.br/ccivil_03/leis/19394.htm>. Acesso em: 08 abr. 2013.

BRISCOE, C. The dynamic interactions among beliefs, role methaphors, and teaching practices: a case study of teacher change. Science Education, Hoboken, v. 75, n. 2, p. 185-199, 1991.

BROOME, R. Conocimientos profesionales de los profesores. Ensenãnza de las Ciencias, Barcelona, v. 6, n. 1, p. 19-29, 1988.

CARVALHO, A. M. P.; GIL-PÉREZ, D. Formação de professores de ciências. 2. ed. São Paulo: Sarvier: FAPESP, 2003.

COLL, C. Psicología y curriculum. Barcelona: Laia, 1987.

COUTO, J. M. As contribuições do ensino-aprendizagem de biologia na prevenção de acidentes com serpentes peçonhentas. 2008. $34 \mathrm{f}$. Trabalho de conclusão de curso (Graduação em Ciências Biológicas) - Faculdade de Educação, Universidade Estadual do Ceará, Itapipoca, 2008.

FRANÇA, F. O. S.; MÁLAQUE, C. M. S. Acidente botrópico. In: CARDOSO, J. L. C. et al. Animais peçonhentos no Brasil: biologia, clínica e terapêutica dos acidentes. São Paulo: Sarvier, 2003. p. 72-86.

FRANCO, F. L. Origem e diversidade das serpentes. In: CARDOSO, J. L. C. et al. Animais peçonhentos no Brasil: biologia, clínica e terapêutica dos acidentes. São Paulo: Sarvier, 2003. p. 13-32.

GATTI, B. A. Formação de professores e carreira: problemas e movimentos de renovação. 2. ed. Campinas: Autores Associados, 2000 (Coleção formação de professores, 1). 
GEBARA, M. J. F. O ensino e a aprendizagem de física: contribuições da história da ciência e do movimento das concepções alternativas - um estudo de caso. 2001. $89 \mathrm{f}$. Dissertação (Mestrado em Metodologia do Ensino) - Faculdade de Educação, Universidade Estadual de Campinas, Campinas, 2001.

GIL-PÉREZ, D. Tres paradigmas básicos en la ensenãnza de las ciencias. Ensenãnza de las Ciencias, Barcelona, v. 1, n. 1, p. 26-33, 1983.

LIMA, D. C.; CASTRO, D. P.; LIMA, F. H. C. O ofidismo e a formação do profissional biólogo no estado do Ceará. In: MORAES, A. C. et al. Vozes da Facedi: reflexões, experiências e perspectivas em educação. Fortaleza: Editora da UECE, 2010. p. 127-140.

LIMA-VERDE, J. S. Por que não matar as nossas cobras. In: NASCIMENTO, L. B.; BERNARDES, A T.; COTTA, G. A. (Ed.). Herpetologia no Brasil I. Belo Horizonte: Editora da PUC/MG, 1994. p. 92-100.

MELGAREJO, A. R. Serpentes peçonhentas do Brasil. In: CARDOSO, J. L. C. et al. Animais peçonhentos no Brasil: biologia, clínica e terapêutica dos acidentes. São Paulo: Sarvier, 2003. p. 33-61.

MISE, Y. F.; SILVA, R. M. L.; CARVALHO, F. M. Envenenamento por serpentes do gênero Bothrops no estado da Bahia: aspectos epidemiológicos e clínicos. Revista da Sociedade Brasileira de Medicina Tropical, Belo Horizonte, v. 40, n. 5, p. 569-573, 2007.

NASCIMENTO, S. P. Aspectos epidemiológicos dos acidentes ofídicos ocorridos no Estado de Roraima, Brasil, entre 1992 e 1998. Cadernos de Saúde Pública, Rio de Janeiro, v. 16, n. 1, p. 271-276, 2000.

PARDAL, P. P. O. et al. Acidente por surucucu (Lachesis muta muta) em Belém- Pará: relato de caso. Revista Paraense de Medicina. Belém. v. 21, n. 1, p. 37-42, 2007.

PEREIRA NETO, A. F. Formação de cientistas: o caso de Vital Brasil (1865/1950). In: SCHIMIDT, B. V.; OLIVEIRA, R.; FRÁGON, V. A. (Org.). Entre escombros e alternativas: ensino superior na América Latina. Brasília: Ed. Universidade de Brasilia, 2000. p. 99-136.

PINHO, F. M. O.; OLIVEIRA, E. S.; FALEIROS, F. Acidente ofídico no estado de Goiás. Revista da Associação de Medicina Brasileira, Brasília, v. 50, n. 1, p. 93-96, 2004.

PINHO, F. M. O.; PEREIRA, I. D. Ofidismo. Revista da Associação de Medicina Brasileira, Brasília, v. 47, n. 1, p. 24-29, 2001.

POUGH, F. H.; JANIS, C. M.; HEISER, J. B. A vida dos vertebrados. 4. ed. São Paulo: Atheneu, 2008.

REAL, M. G. C.; GIANINE, R. J.; FISCHER, H. Z. Acidentes ofídicos atendidos no complexo hospitalar de Sorocaba (São Paulo) entre os anos de 1992 e 1998. Ciência e Biologia Ambiental, São Paulo, v. 2, n. 3, p. 289- 298, 2000. 
Conhecimento do tema ofidismo ...

RIBEIRO, L. A.; JORGE, M. T.; IVERSSON, L. B. Epidemiologia dos acidentes por serpentes: estudo de casos atendidos em 1988. Revista de Saúde Pública, São Paulo, v. 29, n. 5, p. 380-388, 1995.

SANDRIN, M. F. N.; PUORTO, G.; NARDI, R. Serpentes e acidentes ofídicos: um estudo sobre erros conceituais em livros didáticos. Investigações em Ensino de Ciências, Porto Alegre, v. 10, n. 3, p. 281- 298, 2005.

VANZOLINI, P. E.; RAMOS-COSTA, A. M. M.; VITT, L. J. Répteis das caatingas. Rio de Janeiro: Academia Brasileira de Ciências, 1980.

VASCONCELOS, S. D.; LIMA, K. E. C. O professor de biologia em formação: reflexão com base no perfil socioeconômico e perspectivas de licenciandos de uma universidade pública. Ciência \& Educação, Bauru, v. 16, n. 2, p. 323- 340, 2010.

WEN, F. H. et al. Influência das alterações ambientais na epidemiologia dos acidentes ofídicos e na distribuição geográfica das serpentes de importância médica nos estados de São Paulo e Paraná, 1988- 1997. Informe Epidemiológico do SUS, Brasília, v. 11, n. 1, p. 45-47, 2002.

ZAKREVSKI, S.; BIELUCZYK, D.; CICLO, C. Formação de professores em ciências naturais: articulando formação inicial e continuada. In: ENCONTRO NACIONAL DE ENSINO DE BIOLOGIA, 1., E ENCONTRO REGIONAL DE ENSINO DE BIOLOGIA DA REGIONAL RJ/ES, 3., 2006, Rio de Janeiro. Anais... Rio de Janeiro: SBENBIO, 2006. p. 200.

ZANOTTO, M. L. B. Formação de professores: a contribuição da análise do comportamento. São Paulo: Educ, 2000.

Artigo recebido em 12/06/12. Aceito em 27/01/13. 